Dr. A. N. Tucker has visited Uganda and has called a meeting of representatives of teachers, administrators, and others to decide on a method of writing their own language. The need for an 'authorized' consistent orthography has long been recognized, and its achievement will be a vital factor in the literary development of the country.

\title{
Institute of Race Relations for East Africa
}

A movement to establish an Institute of Race Relations for East Africa was inaugurated at a large meeting representative of the African, European, and Indian populations, held at Nairobi on 8 August 1946. The meeting was convened at the request of $\mathrm{H}$.E. the Governor. Similar meetings were held at Mombasa and Dar es Salaam, and were addressed by Mr. Rheinalt Jones (Director of South African Institute of Race Relations) and Mrs. Hellmann.

\section{West African Institute of Industries, Arts, and Social Sciences}

The West African Institute was founded in 1943 with the dual purpose of the investigation and development of local crafts and industries in the light of modern European experience and technique, and the investigation of local culture, social structure, and economic conditions, with special reference to the effects of contact with Western Civilization. Under the guidance of the Institute's enthusiastic director, Mr. H. V. Meyerowitz, a good beginning was made, and valuable research work was done in the study of African Arts and Crafts. Unfortunately, owing to the war and to the death of Mr. Meyerowitz, the activities of the Institute declined. But the importance of the work begun there was such that it was determined to revive it at the earliest opportunity. The West African Council decided that an investigator should be appointed to examine on the spot the technological and sociological research questions connected with the revival of the Institute, and Mr. Henry Morris, Director of Education to the Cambridgeshire County Council, has visited West Africa for this purpose. Mr. Morris, who is well known for his pioneer work in connexion with the village colleges of Cambridgeshire, will make recommendations to the Secretary of State for the Colonies on the organization of sociological and technical research and how these activities may be fitted into the general organization of higher education in West Africa.

\section{Report of Native Production and Trade Commission-Southern Rhodesia I}

THE Commission was appointed in April 1944, with the following terms of reference:

1. Production and marketing of all commodities (whether consisting of livestock, raw agricultural or mineral products, or manufactured or processed articles) produced by natives.

2. The economic or other benefits to be derived by the natives:

(a) from the adoption of co-operative methods of buying and selling both in and outside the native reserves and areas, or of other methods different from those now in use; and

(b) from the establishment of native industries in respect of either existing or new commodities.

3. The desirability of establishing central marketing boards to ensure orderly marketing of native products.

4. The continuation, extension, or abandonment of the system of barter now practised by many natives and the substitution or parallel development of the European method of buying and selling for money.

The report, which is a valuable document, demonstrates the thoroughness with which the Commission undertook this work. Primitive Native agriculture was found to be haphazard and wasteful and the acre return extremely poor. New methods first introduced in 1927 by the Native Agricultural Department are regarded as excellent, but the response

I Government Printer, Salisbury, 1945. Pp. 107. 4s. 3d. 